\title{
Age-Graded Pathways into Crime: Evidence from a Multi-Site Retrospective Study of Incarcerated Women
}

\author{
Sally S. Simpson ${ }^{1} \cdot$ Mariel Alper ${ }^{2} \cdot$ Laura Dugan $^{1}$ • \\ Julie Horney ${ }^{3}$ - Candace Kruttschnitt ${ }^{4}$. \\ Rosemary Gartner 5
}

Received: 18 January 2016 / Revised: 17 August 2016 / Accepted: 22 August 2016 /

Published online: 7 September 2016

(C) Springer International Publishing AG 2016

\begin{abstract}
Purpose The paucity of studies that examine women's criminal careers, particularly beyond the period of young adulthood, has made it difficult for scholars to determine whether developmental pathways - especially precursors of adult-onset offendingvary. This paper examines the onset of offending among women, from childhood to adulthood.

Methods We draw from a retrospective life event calendar administered to women prisoners across three data collection sites. Sorting the women into different onset groups based on self-reports of first time offending, we ask whether there are unique predictors of early, adolescent, and adult-onset status and whether our results are sensitive to the age at which adulthood is measured (18-20 versus 21 and older).
\end{abstract}

The data collection for this research was supported by the National Consortium on Violence Research, the Social Sciences and Humanities Research Council of Canada, and the Graduate School Grant, University of Minnesota.

Mariel Alper Statistician, Bureau of Justice Statistics. The views and opinions presented in this document are those of the author and do not necessarily represent the official opinion and policies of the Bureau of Justice Statistics or the U.S. Department of Justice.

Sally S. Simpson

SSimpson@umd.edu

1 Department of Criminology and Criminal Justice, University of Maryland, College Park, USA

2 Bureau of Justice Statistics, Washington, DC, USA

3 Pennsylvania State University, State College, USA

4 Department of Sociology, University of Toronto, Toronto, USA

5 Centre for Criminology and Sociolegal Studies, University of Toronto, Toronto, USA 
Results In contrast with some criminal career research, this study reveals a sizeable percentage of female offenders who initiate offending in adulthood (43\%). Compared with adult onset, early initiation is associated with childhood sexual abuse, sexual precocity, and low supervision and lack of childhood bonds. Adolescent onset is also associated with some of these same characteristics (compared to adult initiation), but a lack of childhood bonds is unassociated with young adult onset compared to adult initiation. Adult offenders are differentiated by the absence of these risks. Postoffending, young adult starters tend to have, on average, a more extensive criminal history and association with criminal friends, somewhat higher drug involvement (use and drug dealing), and more offense variety than do offenders who initiate after age 21 . Early initiation, and to some extent adolescent onset, tends to reveal more postoffending disadvantages especially when compared with adults.

Conclusions Our findings suggest distinct groups among the adult offenders - one consistent with Thornberry and Krohn's idea of "late bloomers" and another older initiator group for whom the mechanisms of onset remain unidentified.

Keywords Late bloomers · Adult onset $\cdot$ Women's experience of violence sample $\cdot$ Life event calendar

\section{Introduction}

According to Block et al. ([8], p. 75), the "research landscape...is sparsely populated" in terms of studying the long-term patterns of offending in girls and women. There are several important gaps in the criminal career literature as it relates to females (see, e.g. [10]), but one of the most controversial relates to the age of onset. Specifically, some research has suggested that adult-onset offending is a common phenomenon among females $[8,19,20,23,24,34,57,62]$ and that this population of offenders has distinct risk factors in contrast to early or adolescent initiators [49]. Yet, findings from other studies suggest that adult-onset offenders represent a relatively trivial number of offenders overall $[17,42]$ or that there are no true adult onsetters but rather delayed adolescent initiators (Sohoni, Paternoster, McGloin, and Bachman 2011). In short, the empirical literature on this important subject is far from settled.

Our research goal is to provide insight into the following unresolved questions: (1) Do female adult-onset offenders exist and, if so, to what extent are they similar to and distinct from other offending groups (e.g., early and adolescent initiators)? (2) Are adult initiators simply delayed adolescent initiators? We contribute to this literature in the following ways. First, we build on studies that examine onset age among female offenders. Typically, such research relies on a relatively small number of respondents with information collected from one site only [1, 13, 30]. Our study utilizes data collected from 804 incarcerated women held in three different sites: Baltimore County Detention Center, Hennepin County Detention Center for Adults in Minnesota, and Vanier Center for Women in Toronto, Ontario. ${ }^{1}$ Respondents are dispersed across three

\footnotetext{
${ }^{1}$ The principal investigators for each site are Sally Simpson, Candace Kruttschnitt, and Rosemary Gartner, respectively.
} 
cities, two states, and the USA and Canada - a more extensive geographical scope than in most studies.

Data collection methods for the study are distinctive as well. Respondent information was collected using a computerized retrospective life event calendar. This instrument couples survey-type questions about early life experiences with more specific month-to-month information collected for a 3-year period prior to incarceration. Although there are weaknesses with this method (described below), there is reason to believe that the life event calendar generates more accurate recall than traditional survey techniques ([3-6, 22, 27, 63]; [15, 58-60]). ${ }^{2}$

Because the demarcation of adulthood is both conceptually and empirically murky, we also assess whether our results are sensitive to how adult onset is defined and measured. The developmental literature, for instance, highlights key differences between juveniles and adults related to the use of logic and reasoning, ability to control feelings and behaviors, and social development (such as the influence of peers), thus suggesting that there will not be a clear age delineation between juvenile and adult-onset offenders [16]. Because the legal definition of the start of adulthood is age 18 in most states, we compare and contrast early, adolescent, and adult offenders by defining adult onset as age 18 and older and by creating a new category of young adult offenders (aged 18-20) to examine whether this group of offenders resembles adolescent initiators and adult initiators or appears to be distinct. Finally, we compare post-onset variables for all women to see whether life experiences and outcomes differ by onset group.

\section{Literature Review}

The research on age of onset has been influenced by two approaches - the criminal career approach [9, 45] and the developmental/life-course approach [20, 21, 35, 53]. The former has tended to be driven by a set of empirical questions such as when does offending typically begin (initiation), what age differentiates early from late starters, how does onset age structure post-offending patterns, and are there unique observable onset patterns by race, gender, and/or social class? The latter framework focuses on within-individual stability and change in offending and the ways in which life circumstances and experiences affect criminal involvement ${ }^{3}$ over the life course.

We know that there are large variations when individuals first begin to offend. These variations are important because the age at which individuals start to offend determines the configuration of life experiences that may reasonably impact their entry into crime. That is to say, while early-onset offending must be explained by childhood variables, adult-onset offending may be explained by experiences that occur during and long after childhood. Our goal in this review section is to identify empirical patterns and explanatory factors related to age of onset. With our focus on female offenders and adult onset, we give special attention to relevant research on gender and, in particular, female patterns.

\footnotetext{
${ }^{2}$ Reviews of the life event calendar and its use in social science research are provided by Roberts and Horney [46] and Glasner and van der Vaart [26].

${ }^{3}$ References to illegal or criminal involvement in this paper refer to respondent self-reported offending. Selfreported victimization is not included in the term.
} 


\section{Age of Onset: Operationalization and Empirical Patterns}

To begin our review, it is important to clarify the term "adult" onset as many different definitions and terms commonly differentiate those whose offending careers start later than at some point during adolescence. For some, the term "late onset" has been used to refer to anyone who is not an early starter, so under this definition, a late starter would include those who begin offending during the modal ages of adolescence and later (e.g. $[40,44])$. For others, it refers to those who begin offending in late adolescence and early adulthood ("late bloomers"), rather than exclusively post-adolescent (e.g. [53]). Others use the term "adult onset" to refer to stages of life that correspond to maturational development, transition into adult roles, or adult justice processes (see [20, 34, 39, 64]; Sohoni et al. 2014). In this study, we prefer the term adult onset to describe offenders who initiate offending after the age of 18 , when the transition to formal/legal adult roles begins.

Some research suggests that adult-onset offenders are highly unusual [41], but there is not a substantial body of research on post-adolescent offenders to back up this assertion [20]. The paucity of studies may be due to the fact that many datasets are truncated during early adulthood and researchers can only hint at patterns that have yet to emerge. For instance, in their prospective cohort study, Moffitt and her colleagues ([42], p. 85) report that only $3 \%$ of males and $5 \%$ of females first offend as adults (age 18). Yet, these results are based on participants only through age 21 . Similarly, in her analysis of criminal onset in emerging adulthood, Couture's adults from Wave 7 of the National Youth Survey are limited to ages 21 through 27 ([17], p. 67). She too finds a limited number of adult offenders (only $5.6 \%$ of the male offenders and $12.7 \%$ of the female offenders). In contrast, Eggleston and Laub's [20] review of the cohort literature concluded that adult-onset offending (officially defined) characterized a substantial portion of the adult offender population (on average, 50\%) - a figure that is even higher "among the "female adult population"".

Numerous studies have found a higher prevalence of adult-onset offending for females than males (c.f. [8, 19, 23, 24, 34, 57, 62]). For example, using a cohort sample of males and females born in Stockholm in 1953 and residing there in 1963, Kratzer and Hodgins [34] defined adult onset as those cohort members who had a criminal conviction as an adult (after 18) but not before. Based on these criteria, they identified a substantial number of adult-onset offenders for both sexes-39\% of all male offenders had no convictions until after the age of 18 compared with $52 \%$ of the female offenders. In fact, this group of offenders constituted the largest group in their sample for both sexes; further, they confirmed that most adult initiators did not have unofficial records of adolescent delinquency ${ }^{4}$ - a finding that suggests that these are true adult-onset offenders and not just criminals who managed to avoid an official record until adulthood. Other scholars, however, have found no gender difference or a higher prevalence of adult initiation among males (c.f. [14, 28, 29, 55, 56, 61]). GomezSmith and Piquero [29], for instance, found that females were less likely than males to be adult-onset offenders (5.6 and $25.0 \%$ of the sample, respectively) in their study of African American males and females who participated in the Philadelphia portion of

\footnotetext{
${ }^{4}$ Unofficial records in this study refer to delinquent acts committed during adolescence reported by a social service agency (child welfare) that did not result in prosecution.
} 
the National Collaborative Perinatal Project (NCPP). Adult-onset offenders were defined as those who had no police contact prior to age 18 and at least one conviction at age 18 or older.

Such divergent patterns in the prevalence of adult-onset offending among females are likely a by-product of diverse samples, discrete data sources, and different ways of measuring key concepts. For instance, some studies utilize cohort or general population samples while others rely on at-risk or offender populations. The initiation event may capture onset by using official records and/or self-reports. Studies also may differ in the cutoff age used to define adulthood [8, 39]. The age designation is imprecise and consequently varies empirically. Most often, age 18 is used to distinguish adult onset (c.f. [34]), but sometimes, age 21 is used (c.f. [64]; Hayatbakhsh, Najman, McGee, Bor, and O'Callaghan 2008) or even age 25 (c.f. Sohoni et al. 2014), resulting in very large differences in estimates of the prevalence of adolescent and adult-onset offenders. As mentioned previously, the age at which the sample is truncated may also influence prevalence, as an earlier final cutoff age may miss offending that begins even later in life [36].

Adult-onset offenders may be more or less difficult to identify depending on what statistical method is used. For instance, when Couture [17] used group-based trajectory models to estimate offender groups, the analysis failed to identify late-onset offenders in the National Youth Survey data. However, when she changed her methods to between-individual comparison models, a small number of late/adult initiators were revealed. Finally, data sources also are highly contextualized by time and place such that social changes or significant historical events may uniquely affect cohort populations. There may be distinctive onset patterns for different populations (stratified by nationality, gender, ethnicity, and race) or cultural shifts that may affect criminal initiation at particular points in time (e.g., World War II). While it is likely that sample characteristics influence estimates of prevalence, the wide variety of samples make it clear that adult-onset offenders are present in numerous populations, albeit in different proportions.

In the next section, we review what is known about the different predictors of early, adolescent, and adult onset. Although our study focuses on female offenders, the extant literature on female initiation is relatively rare compared with that of males. Consequently, our review draws broadly from the literature with an emphasis on studies that focus only on female offenders or on female offenders who are compared with male offenders.

\section{Accounting for Different Onset Patterns}

Age plays an important role in many theories of criminal offending. Criminal career, developmental, and life-course explanations for offending initiation are built around the idea that age matters [36, 40, 44, 48]. As Blumstein et al. ([9], p. 13) observe, a "different set of 'causes' may influence individuals' decisions to initiate criminal or delinquent activity." And yet, processes related to the activation and aggravation of a criminal career do not occur merely as a function of an individual's chronological age [37]. This suggests that delinquents who offend early in life are exposed to a distinct set of etiological factors compared with later-onset offenders (i.e., their paths into crime differ). Gender-related differences in developmental processes over the life course such as early pubertal maturation, transition into adulthood, or risk of death will affect 
behavior patterns, including antisocial behavior ([11]; Hayatbakhsh et al. 2008; $[12,30])$. For these reasons, failure to include adult-onset offenders when studying female offenders may produce incomplete or, worse yet, highly misleading empirical (and subsequently theoretical) conclusions.

The small but growing body of research on the predictors of adult-onset offending gives some clues as to the causal pathways for this onset group as well as how situations and conditions may vary by race, gender, and cohort. However, findings are far from conclusive. For example, Zara and Farrington [64] found that late starters (defined as those who had no official record until age 21 or later) differ from early starters on many childhood, adolescent, and teenage predictors. They are more likely to be nervous and socially isolated in childhood and come from poor neighborhoods; are more likely to be anxious, have low verbal IQ, and leave school prematurely in adolescence; and are more likely to display high neuroticism and difficulty establishing intimate relationships as a teenager. By adulthood, however, the adult-onset group shares similar characteristics with the early starters, although they are less likely to be hospitalized for psychological treatment or self-report heavy drinking or drug use. Similarly, Thornberry and his collaborators $[53,54]$ discover a sizeable number of "late bloomer" (post- 18 to 21) offenders in the Rochester Youth Development Study (RYDS). Using group trajectory models and self-reports of offending, Thornberry and Matsuda [54] found late bloomers are essentially "indistinguishable" from nonoffenders in their rate of offending during adolescence, but post-adolescence, their criminal careers escalate attaining a rate of crime similar to persistent offenders. Thornberry and Krohn [53] suggest that late bloomers demonstrate "off-time" transitions largely as a result of breaking away from strong bonds to family and other institutions that served as a protective barrier to earlier offending. Late bloomers, however, exhibit individual deficits that, absent strong bonds, manifest in persistent and non-trivial involvement in criminal behavior during the adult years. In other words, the late blooming group can be differentiated by their human capital deficits and the weakening of constraints as they approach young adulthood [54].

In a similar vein, Eggleston and Laub [20] found more similarities than differences between adult- and juvenile-onset offenders. Demographics, childhood and family measures, adolescent and adult peer and drug use variables, and education measures did not differentiate late-onset and persistent (childhood onset) offenders. However, employment in adulthood was positively associated with offending for adult-onset offenders but had no effect for persistent offenders. However, the authors attribute this one significant finding to chance. Their adult-onset group consisted of those who had police contact at age 18 or later for non-traffic or non-status offenses, but no prior police contact.

In a study of female offenders, Baskin and Sommers [1, 2] found that "early adulthood" offenders (based on self-reported offending; exact ages were not given from their qualitative data) were less likely to come from a family with a history of psychiatric hospitalization, but they were similar to the early-onset group in terms of parenting styles and supervision, physical and sexual abuse, and parental criminality. Adult starters were also less likely to come from neighborhoods with a high concentration of poverty, to experience childhood physical or sexual abuse by strangers, or have school peers involved in crime. In addition, alcohol or drug use at school was less prevalent among adult starters and they tended to have a later initiation into drug use compared 
with their early initiation peers. Gunnison and McCartan [30] also found that adult-onset females differed from their juvenile-onset persistent offender counterparts. The adultonset group (defined as those who did not experience a self-reported arrest or incarceration before adulthood) was less likely to experience alcohol and drug use, physical and sexual abuse, depression, association with gangs and criminal acquaintances, as well as head injury early in life.

Finally, data from one of the three sites examined in this project (Baltimore) revealed that self-reported adult-onset offenders had few of the risk factors associated with childhood- or adolescent-onset offenders. This mostly African American sample tended to have a fairly stable lifestyle, but they did have more exposure to violent victimization such as rape, robbery, and assault by partners and non-partners than the other onset groups [49].

The studies just reviewed vary greatly in how they classify and measure adult onset (what age, whether self-report or official data is used) as well as in their sample characteristics (ethnicity, gender, follow-up age, time period, country) and predictive variables included. For example, there are large variations between Zara and Farrington's [64] sample of London males born in the 1950s, Eggleston and Laub's [20] sample of men and women born in the 1940s in Wisconsin, Baskin and Sommers' [1] contemporary sample of mostly African American women arrested for felonies in New York City, and Gunnison and McCartan's [30] sample of incarcerated females. These differences likely help explain why some studies found differences in childhood and adult characteristics of early- versus adult-onset offenders, while others found more similarities. For instance, if we take education as an example, some studies find that late-onset offenders were more likely to have dropped out of school [64] or there was no difference in the effects of dropping out for the two groups [20]. One study found that adult-onset offenders more likely to have been truant at school $[1,2]$ but others do not assess education at all [30]. Similar inconsistencies are notable with other variables such as deviant peers/social isolation [1, 2, 20, 30, 54, 64]. By studying a large and diverse sample of women drawn from several locations in the USA and Canada, measuring onset in the same way through offender self-reports, and assessing a large number of key variables, we hope to provide a more comprehensive and detailed review of offending onset patterns for women.

\section{Post-Onset Patterns}

Developmental and life-course perspectives focus on transitions into trajectories that set a person on a path that may "impede one's progress to a desired outcome or goal" ([33], p. 184). From this perspective, delinquent/criminal behavior and the resulting negative structural consequences (such as official sanctions) have implications for a person's "pattern or level of functioning at some later time" ([47], p. 64). Laub and Sampson ([35], see also [18]) refer this dynamic process as "cumulative disadvantage" whereby participation in delinquency and crime can lead to school failure, jail and prison, lost opportunities in the labor market, and broken ties with family and friends which, in turn, increase the risk of crime (i.e., stability of offending). This revitalized labeling theme has been explored and validated empirically by Bernburg and Krohn [7] and Lopes et al. [38]. In Moffitt's [40] developmental typology of life-course persistent (LCP) offenders and adolescent-limited (AL) offenders, she differentiates distinct 
causes (biological versus social) and consequences of criminality (persistence versus desistence) for the different groups. Her LCP offenders are expected, post-onset, to have more extensive criminal careers, more variety to their offending, and more negative life outcomes compared with the AL offenders who ultimately desist from crime without the deleterious consequences.

Rather than treating these different approaches as distinct, we utilize all of them to develop research hypotheses and draw conclusions from our analyses. We expect that onset age will have an effect on post-onset life experiences and outcomes, including both criminal behavior and conventional opportunities (such as marriage and employment). Because our sample, described below, had not desisted before they were incarcerated, we do not expect to see the same stark contrasts between early and adolescent offenders that Moffitt's taxonomy predicts. However, we do expect childhood offenders to have more extensive criminal careers and less positive social outcomes post-offending compared with adolescent initiators. While Moffitt has dismissed the idea of adult-onset initiators (and thus her taxonomy provides no guidance for post-offending expectations for this group), results from Gunnison and McCartan's study of incarcerated female offenders suggest that the post-onset offending lives of adult initiators will be more stable and less criminogenic than either childhood or adolescent initiators.

\section{Sample, Methods, and Analytic Approach}

\section{Sample}

Funded by the National Consortium on Violence Research and the Social Sciences, ${ }^{5}$ the Humanities Research Council of Canada, and the Graduate School at the University of Minnesota, the Baltimore, Minnesota, and Toronto Women's Experience of Violence data were collected retrospectively using a computerized life event calendar initially developed by Horney ([32]; see also [46]) and modified by the project principal investigators (Horney, Gartner, Kruttschnitt, and Simpson) and other experts. ${ }^{6}$ Although the instrument and administration techniques were the same in each site (more on this below), the population of women offenders from which the samples were drawn differed slightly from place to place.

In the Baltimore City Detention Center (BCDC, previously known as the Baltimore City Jail), women over 18 years of age were selected from the general population. ${ }^{7}$

\footnotetext{
5 The National Consortium on Violence Research (NCOVR) was funded through a Cooperative Agreement (No. SBR-9513040) between the National Science Foundation and Carnegie Mellon University. Its primary mission was to promote integrated, multidisciplinary research into the causes of violence; educate a new generation of research investigators; conduct outreach to policymakers and practitioners involved in dealing with violence; and institutionalize the research, education, and outreach functions in an ongoing organization.

${ }^{6}$ Dr. Kathleen Ferrero, Dr. James Lynch, and Brian Wiersema participated in the modification efforts. In addition, the instrument was vetted with several practitioners who work closely with domestic violence victims.

${ }^{7}$ At the time of the interviews, the Baltimore City Detention Center was one of the largest municipal jails in the nation with over 40,000 inmates (males and females) committed to the center annually. The daily number of inmates averages over 3000. The Center is a pretrial detention facility for any person committed or transferred to the custody of the Commissioner of Pretrial Detention and Services.
} 
Some of the women already had a preliminary hearing before the court and were awaiting sentencing (which could be served in the detention center). Others already had been sentenced and were serving their term in the detention center or were awaiting transfer to a different facility. Over the 14-month period during which the study ran (2001-2002), BCDC staff recruited women held in the center for possible participation in the study. Three hundred sixty-one women were given the opportunity to participate in the study. Only six refused to be interviewed (98\% response rate), but an additional four were transferred, released, or stopped the interview before it was complete. Therefore, the final number of valid interviews completed was 351 .

In Minnesota, data were collected from a smaller but similar group of offenders. Between June 2002 and December 2004, researchers contacted 230 women from the female population incarcerated in the Hennepin County Adult Detention Center in Minnesota. Some of the women contacted refused to participate in the study (25) resulting in 205 completed interviews (for a response rate of $89 \%$ ). The Hennepin County Detention Facility is a short-term jail that, like the Baltimore facility, houses both males and females. Women who were serving traditional sentences ${ }^{8}$ were selected from rosters of the total jail population based on nearest approaching release dates.

A third sample of women offenders was obtained from the Vanier Centre for Women, a provincial correctional facility in Southern Ontario, Canada. Vanier houses women with sentences of less than 2 years. Interviews were conducted between 2001 and 2004. Only two women, out of the 263 women who volunteered to be interviewed, declined to participate after learning more about the study. Another respondent withdrew shortly after beginning the interview, resulting in a response rate of $98.8 \%$. Twelve women were unable to complete all sections of the interview due to scheduling problems leaving a total of 248 women in the final group of participants.

Although women who participated in these interviews were drawn from convenience samples, their demographic and criminal history information are comparable to incarcerated female inmates within the correctional facility from which the study population is drawn. In the aggregate, the WEV sample population is disproportionately minority women $(63 \%)$, most of whom are Black $(49 \%){ }^{9}$ The average age of respondents is 34 , with an age range of 18-62. These women are typically unmarried $(83 \%)$ and mothers (80 \%), who had children living with them at the time of their arrest $(51 \%)$. About half of the participants $(49 \%)$ graduated from high school or received their General Educational Development (GED), but a substantial number reported being unemployed for the entire 3 years prior to their current incarceration (39\%). The most common current offense for respondents (for which they were serving a sentence or awaiting disposition) was drug-related (32\%), and many respondents reported criminal records and past experience with the criminal justice system (e.g., arrests, jail, and/or prison terms). ${ }^{10}$ All-in-all, these women are fairly typical of incarcerated women in the USA and Canada.

\footnotetext{
8 Those serving weekend or "shock" incarceration sentences were excluded from the sampling frame.

${ }^{9}$ In Toronto, three fourths of the respondents were White. While the largest group of respondents in Minneapolis also was White (42\%), the sample had more of an ethnic/racial mix than either Baltimore or Toronto (e.g., $20 \%$ American Indian and $32 \%$ Black). Due to the potential for important contextual differences, our analyses include dummy codes for the specific data collection sites.

${ }^{10}$ Sixty-percent had been convicted of a felony prior to their current incarceration, $59 \%$ had served at least one jail term as an adult, and $98 \%$ had been arrested at least one before.
} 


\section{Survey Administration}

As noted, data were collected using a computerized life event calendar. To facilitate communication and build trust between the interviewer and respondent, the researcher and participant typically were seated side-by-side in private rooms, away from correctional staff and other inmates. Interviewers outlined the research objectives of the study and assured women that they would be guaranteed confidentiality and that they could withdraw from participation at any point in the data collection process. After reviewing the research procedures, women willing to participate signed a consent form. For their participation, women were given a small incentive (except in Toronto where the institution did not allow this). Each semi-structured interview took between 1.5 and $8 \mathrm{~h}$ to complete; the average interview lasted approximately $3 \mathrm{~h}$. The interview schedule, which was programmed onto laptop computers, included information on women's incarceration and treatment experience, living arrangements, routine and criminal activities, and intimate relationships in the 36 months before their current incarceration. There were also demographic and some childhood experience questions. These interviews yielded extensive quantitative information from the life event calendar as well as narrative details about violent experiences (or potentially violent experiences) in which the respondent was a participant (including both partner and nonpartner violence). For this study, we rely on the 36-month calendar, demographic, and childhood experience data.

An important strength of life event calendars is that, in contrast to traditional surveys, they facilitate accurate recall by using key time markers to situate life events. This method draws on what is known about the storage of autobiographical memory and is designed to improve recall over traditional survey methods. Evaluations of calendar instruments have shown that they increase the completeness of respondents' accounts, reduce gaps in time unaccounted for, improve accuracy in the number and characteristics of reported events, enhance consistency, reduce time dating errors, and improve recall for less recent, more frequent, and less salient events [26]. Life event calendars appear to improve recall and obtain higher quality data, and traditional survey methods are rarely more effective [46]. Additionally, the use of retrospective life event calendars eliminates the need to repeatedly survey the same respondents as longitudinal data collection requires, reducing bias resulting from selective attrition, "respondent fatigue," and other testing effects [43].

On the other hand, apparent consistency and completeness of the data gathered through calendar instruments may reflect biased reconstructions rather than higher validity [26]. For example, asking a respondent to fill a gap of time that is unaccounted for may not be a good idea if the respondent cannot remember the episode during the gap and instead stretches previous or subsequent episodes in order to fill the period. Additionally, even life event calendars cannot overcome the difficulty of recall in some cases, such as recalling specific violent events for respondents who frequently are involved in high rates of violence, or recall for respondents with characteristics that limit their accuracy, including mental health or substance abuse problems [46]. However, even though the life event calendar cannot solve every issue related to accurate recall of life events, it is a clear improvement over traditional survey methods. 


\section{Analytical Approaches}

We defined age of onset as the age at which a woman reported she first became involved in crime. We then sequentially ran two multinomial logistic regressions to determine (1) which childhood predictors discerned whether women became childhood- (up to age 12), adolescent- (age 13-17), young adult (age 18-20), or adult-onset (age 21 or older) offenders and (2) which childhood and adolescent predictors discerned adolescent-, young adult-, and adult-onset offenders. The first multinomial regression was run on the full sample to predict whether the respondent's first offense was during childhood, adolescence, young adulthood, or as an adult. The independent predictors only include variables that theoretically preceded (or co-occurred with) childhood. The second multinomial regression included only those respondents who had not already begun offending during their childhood. It predicts adolescent, young adult, and adult onset using both childhood and adolescent measures as independent variables. In both models, the adult-onset outcome is used as the reference group so that the presented relative risk ratios are relative to adult-onset, allowing us to directly discern how adult-onset female offenders differ from other onset groups. We also test for differences in predictors between the younger groups. Note that we discern young adult- and adult-onset groups in order to determine whether females who begin to offend in early adulthood have a distinct set of predictors or whether their predictors resemble those for adolescent or adult initiators.

In order to assess whether the three onset groups have different experiences after beginning their offending, we test for differences in the averages of post-onset variables across all four groups. We generated these conditional averages (and proportions) by calculating predicted values from regressions (logistic or OLS), setting the post-onset variables as dependent variables (e.g., conventional opportunities, criminal history, and victimization experiences), and regressing them on the onset groups while controlling for the age at the current arrest. The age at arrest was used as a control because that value is likely strongly related to the post-onset variables and the onset groups (i.e., older women have more experiences). We report the predicted values for each onset group (setting the age at arrest to its average) and whether they differ significantly by onset group (i.e., $t$ tests of the regression coefficients).

\section{Findings}

\section{Age of Onset}

In our sample, a similar percent of women report adult (43\%) and adolescent (40\%) onset when adult onset is measured at age 18 and older. A smaller group (17\%) includes child initiators (12 and under). ${ }^{11}$ If we shift our definition of adult onset to age 21 and older, adult-onset offenders constitute $31 \%$ while young adults (18-20) constitute nearly $12 \%$ of the women in the sample. Clearly, there is a large difference in classification depending on how adult onset is defined and measured. This observation is reinforced by the average age of onset within the categories. For instance, the average age of onset for child initiators is 10.5 while the average age for adolescents is nearly 15

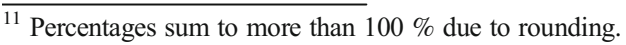


(14.8). Our young adult initiators cluster on the younger side of the classification (18.7). The adults, however, have a relatively older average onset age (29).

In Table 1, we present the findings that show whether childhood predictors are distinctly associated with different onset ages. ${ }^{12}$ Each column presents the relative risk ratios (RRRs) that compare the effects of the predictor on belonging to the specific onset group relative to belonging to the adult-onset group. We also include in the additional three columns indicators of significance for the tests between the RRRs for each group. For example, if the female experienced childhood sexual abuse, she was 1.8 times more likely to have offended during her childhood than to have offended in adulthood. The experiences of childhood sexual abuse are statistically similar for adolescents and young adults relative to adults. The significance indicators show that those who experienced childhood sexual abuse were also more likely to begun offending during childhood than during young adulthood (ac), although there appears to be no statistical difference between its effects on childhood versus adolescent onset (ab). Several other important findings emerge in this analysis. First, when we examine the overall patterns in this table, it is clear that, generally, the young adult-onset group looks more like the adult-onset group than the adolescent-onset group. The only factor that distinguishes young adults from adults is the age at current arrest. This variable should systematically distinguish all groups from adults because those who began offending as adults must be at least adult age during the current arrest, whereas those who began offending at an earlier age can be closer to 18 . However, we also observe that the only factor that distinguishes young adult predictors from those of adolescence (bc) is the lack of childhood bonds. Further, Table 1 also shows that the childhood- and adolescent-onset groups share all predictors except for childhood sexual abuse.

As mentioned above, experiencing childhood sexual abuse increases the odds of childhood onset by $81 \%$ relative to having started offending as an adult and also increases the chances of childhood onset relative to young adult onset. Table 1 also shows that respondents who had consensual sex before age 13 and who lacked supervision and childhood bonds were more likely to begin offending during childhood and adolescence than during adulthood. More specifically, those who had sex prior to age 13 were nearly six times more likely to begin offending during childhood than adulthood and more than twice as likely to initiate offending during adolescence than during adulthood. Further, although this group is more likely to begin offending during childhood than adolescence, there is no evidence that they are any more or less likely to begin offending as young adults compared to other ages. Lacking supervision and childhood bonding appear to similarly affect whether the respondent began offending during childhood or adolescence. Yet, lacking childhood bonds increases the chances of onset during either childhood or adolescence rather than as a young adult. However, those who lacked supervision during childhood are just as likely to begin offending during childhood, adolescence, or young adulthood. Finally, there is an increased risk of childhood and adolescent onset in Minnesota, relative to adult-onset.

Turning to Table 2, we now can observe which adolescent predictors are estimated to discern onset at different ages. Once again, the RRRs are presented, which show the risk of belonging to the adolescent- and young adult-onset groups relative to belonging to the adult group. The final column shows whether the predictors significantly differ

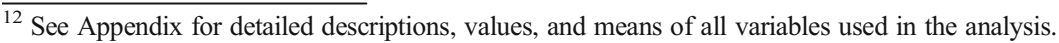


Table 1 Multinomial regressions predicting childhood-, adolescent-, and young adult-onset offending (relative risk ratios)

\begin{tabular}{|c|c|c|c|c|c|c|}
\hline Variable & $\begin{array}{l}\text { Childhood } \\
\text { onset }^{\text {a }} \text { (a) }\end{array}$ & $\begin{array}{l}\text { Adolescent } \\
\text { onset }^{\mathrm{a}} \text { (b) }\end{array}$ & $\begin{array}{l}\text { Young adult } \\
\text { onset }^{\mathrm{a}}(\mathrm{c})\end{array}$ & $\mathrm{ab}$ & ac & $\mathrm{bc}$ \\
\hline Age at arrest & $0.884 * * *$ & $0.918 * * *$ & $0.941 * * *$ & $* *$ & $* * *$ & NS \\
\hline Black & 0.614 & 0.728 & 0.824 & NS & NS & NS \\
\hline Native American & 1.503 & 1.007 & 1.244 & NS & NS & NS \\
\hline Other race & 0.620 & 0.865 & 0.229 & NS & NS & NS \\
\hline Raised by both parents & 0.697 & 0.822 & 1.248 & NS & NS & NS \\
\hline $\begin{array}{l}\text { Childhood sexual abuse } \\
\text { (before 6th grade) }\end{array}$ & $1.811^{*}$ & 1.350 & 1.239 & NS & $* * *$ & NS \\
\hline First sex in childhood & $5.822 * * *$ & $2.372 *$ & 1.086 & $* * *$ & NS & NS \\
\hline Lack of supervision & $1.254 * *$ & $1.157^{*}$ & 1.114 & NS & NS & NS \\
\hline Lack of childhood bonds & $1.071^{*}$ & $1.054 *$ & 0.973 & NS & $*$ & $*$ \\
\hline Baltimore & 0.564 & 0.690 & 1.190 & NS & NS & NS \\
\hline Minnesota & $1.471^{*}$ & $2.025^{*}$ & 2.084 & NS & NS & NS \\
\hline Constant & $5.278^{*}$ & $8.782 * * *$ & 2.817 & & & \\
\hline Pseudo $R^{2}$ & 0.1202 & & & & & \\
\hline$n$ & 776 & & & & & \\
\hline
\end{tabular}

All relative risk ratios greater than 1.0 are associated with an increased likelihood of belonging to the specific onset group relative to the adult group, and all relative risk ratios less than 1.0 are associated with a decreased likelihood. Pseudo $R^{2}$ was calculated as 1 minus L1/L0 where L1 is equal to the full model log likelihood and $\mathrm{L} 0$ is equal to the log likelihood of a model containing only the constant

$N S$ not significant

$* p \leq 0.05 ; * * \leq 0.01 ; * * * p \leq 0.001$, all tests are one-tailed

${ }^{\text {a }}$ Reference group is adult-onset offenders (onset at age $21+$ )

for the adolescent- and young adult-onset groups. Overall, we again observe that predictors for the young adult group are statistically similar to the adult group, as the only difference is the age at arrest, which is expected. Further, the young adult-onset group differs from the adolescent group for the same three risk factors that distinguish the adolescent group from the adult group. The new finding in this table is that those females who first experienced sex during adolescence are nearly three times more likely to also begin offending during adolescence than during adulthood and during young adulthood $(\mathrm{RRR}=2.59)$. We find that those females who experienced physical abuse before the age of 18 or had graduated from high school (or its equivalent) were just as likely to begin their career during adolescence as in young or older adulthood.

\section{Post-Onset Analysis}

We now compare the predicted values for post-onset variables that control for the age of arrest, setting it at its average (34.196). This allows us to differentiate any additional dimensions between the offending onset groups and, in particular, differences between young adult and adult onset (see Table 3). The predicted values for the conventional opportunity and life contingency variables post-offending show key differences across all 
Table 2 Multinomial regressions predicting adolescent- and young adult-onset offending (relative risk ratios)

\begin{tabular}{llll}
\hline Variable & Adolescent onset ${ }^{\mathrm{a}}$ (a) & Young adult onset $^{\mathrm{a}}$ (b) & ab \\
\hline Age at arrest & $0.920^{* * * *}$ & $0.936^{* * *}$ & $\mathrm{NS}$ \\
Black & 0.781 & 0.786 & $\mathrm{NS}$ \\
Native American & 1.124 & 1.214 & $\mathrm{NS}$ \\
Other race & 0.886 & 0.228 & $\mathrm{NS}$ \\
High school graduate/GED & 0.802 & 0.654 & $\mathrm{NS}$ \\
Raised by both parents & 0.874 & 1.370 & $\mathrm{NS}$ \\
Childhood physical abuse (before 18) & 1.012 & 0.786 & $\mathrm{NS}$ \\
Childhood sexual abuse (before 6th grade) & 1.278 & 1.292 & $\mathrm{NS}$ \\
First sex in childhood & $5.189^{* * *}$ & 1.095 & $* *$ \\
First sex in adolescence & $2.727^{* * *}$ & 1.053 & $* *$ \\
Lack of supervision & 1.109 & 1.142 & $\mathrm{NS}$ \\
Lack of childhood bonds & $1.059^{*}$ & 0.981 & $*$ \\
Baltimore & 0.591 & 1.186 & $\mathrm{NS}$ \\
Minnesota & 1.762 & 3.551 & $\mathrm{NS}$ \\
Constant & 4.394 & 3.551 & 0.1215 \\
Pseudo $R^{2}$ & 0.1215 & & \\
$n$ & 646 & &
\end{tabular}

All relative risk ratios greater than 1.0 are associated with an increased likelihood of belonging to the specific onset group relative to the adult group, and all relative risk ratios less than 1.0 are associated with a decreased likelihood. Pseudo $R^{2}$ was calculated as 1 minus L1/L0 where L1 is equal to the full model log likelihood and L0 is equal to the log likelihood of a model containing only the constant

$N S$ not significant

$* p \leq 0.05 ; * * p \leq 0.01 ; * * * p \leq 0.001$, all tests are one-tailed

${ }^{a}$ Reference group is adult-onset offenders (onset at age $21+$ )

categories - demographic, offense history, illegal/antisocial activity, and victimization (see the Appendix). ${ }^{13}$ Many but not all of these differences are observed between the young adult and adult initiation offender groups (cd). For instance, young adult offenders are less apt to be married compared with adult-onset offenders and more apt to have friends in prison and friends with felony convictions than do adult initiators. Similarly, the young adults have a more substantial offending history than do the adults (more lifetime arrests, lifetime jail terms, lifetime prison terms, and lifetime felony convictions). However, there are no significant differences between the early and later adult-onset groups with regard to whether they were employed at the time of their arrest.

The same patterns are not revealed, however, when we compare adolescent with young adult starters. In fact, adolescent and young adult offenders (bc) do not differ from one another on any demographic/life contingencies or offense history variables save two, lifetime arrests and lifetime jail terms but they differ from the adult initiators

\footnotetext{
${ }^{13}$ Because the post-onset variables reflect cumulative disadvantage effects (i.e., the consequences of offending) and not predictors of offending initiation per se, we do not include variables that were used in the previous analyses reported in Tables 1 and 2.
} 
on all of these dimensions (bd) as do childhood onsetters (ad). Offenders who initiate in childhood have significantly more lifetime arrests and more lifetime jail terms than adolescent initiators $(\mathrm{ab})$, but there are no differences in lifetime prison terms or lifetime felony convictions between child, adolescent, or young adults. On the other hand, all three groups differ from adult starters.

While late bloomers are expected to have persistent criminal careers post initiation, if the adult-onset offenders are the same as late bloomers (Sohoni et al. 2014), we would not expect to see any offense history differences between the young adults and the adults. Yet, these differences are apparent and reinforced when we look more specifically at the kinds of crimes and antisocial activity reported by the women. Compared with young adult offenders (cd), adult initiators score lower on the crime variety index (drug dealing, fraud/forgery, theft/auto theft/burglary, prostitution, and robbery/non-partner assault/rape) and they are significantly less involved in using and dealing drugs. Involvement in property crime differentiates all offender groups from one another except for young adult and adult initiators. And offenders who begin offending in childhood exhibit substantially more variety in their offending than any of the other groups. Adolescent initiators, on the other hand, show more offense variety than adult initiators, but they do not differ from the young adult group. It is also apparent that both childhood and adolescent starters, while not significantly different from one another, are more apt to be partnered with property offenders than young and adult initiation groups. Adolescent initiators appear to be somewhat more likely to be partnered with drug dealers (compared with both groups of adult starters), and the partners of both child and adolescent groups are more apt to have used drugs compared with the adult initiation groups. Notable as well, however, are the variables for which we observe no significant differences in predicted values for the onset groups, including drug dealing with a family member, property offending with family, ${ }^{14}$ partner alcohol use, and respondent alcohol use. Overall, the post-onset patterns suggest that both child and adolescent starters are more involved in illegal and anti-social behavior (with partners) compared with the adult initiators.

The regressions for violent experiences also show interesting patterns by initiation group. We found no differences between the groups regarding their experience of violent victimization and using violence defensively in the context of victimization but childhood initiators were more apt than young adult and adult-onset groups to engage in offensive violence (regardless of whether they had been victims of violence or not). A similar difference is revealed for young adults compared with adult initiators. We also observe differences in predicted values for partner and non-partner victimization incidents that were too numerous and too similar to others for the respondent to accurately recall unique details, e.g., series incidents. Here, we see that childhood initiators were significantly more likely to report these kinds of events (involving partners and nonpartners) than were respondents who initiated in adolescence or in adulthood (early or later). In a similar vein, adolescent starters reported higher levels of non-partner series events than did adults, but they did not differ significantly from young adults. Again, our results point to an adult initiation group that is more stable, has fewer criminal associates, and is less involved with or victimized by illegal behavior.

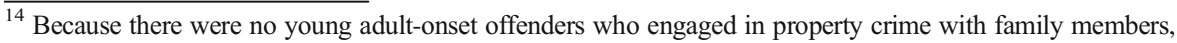
we were unable to include this group in regression model.
} 


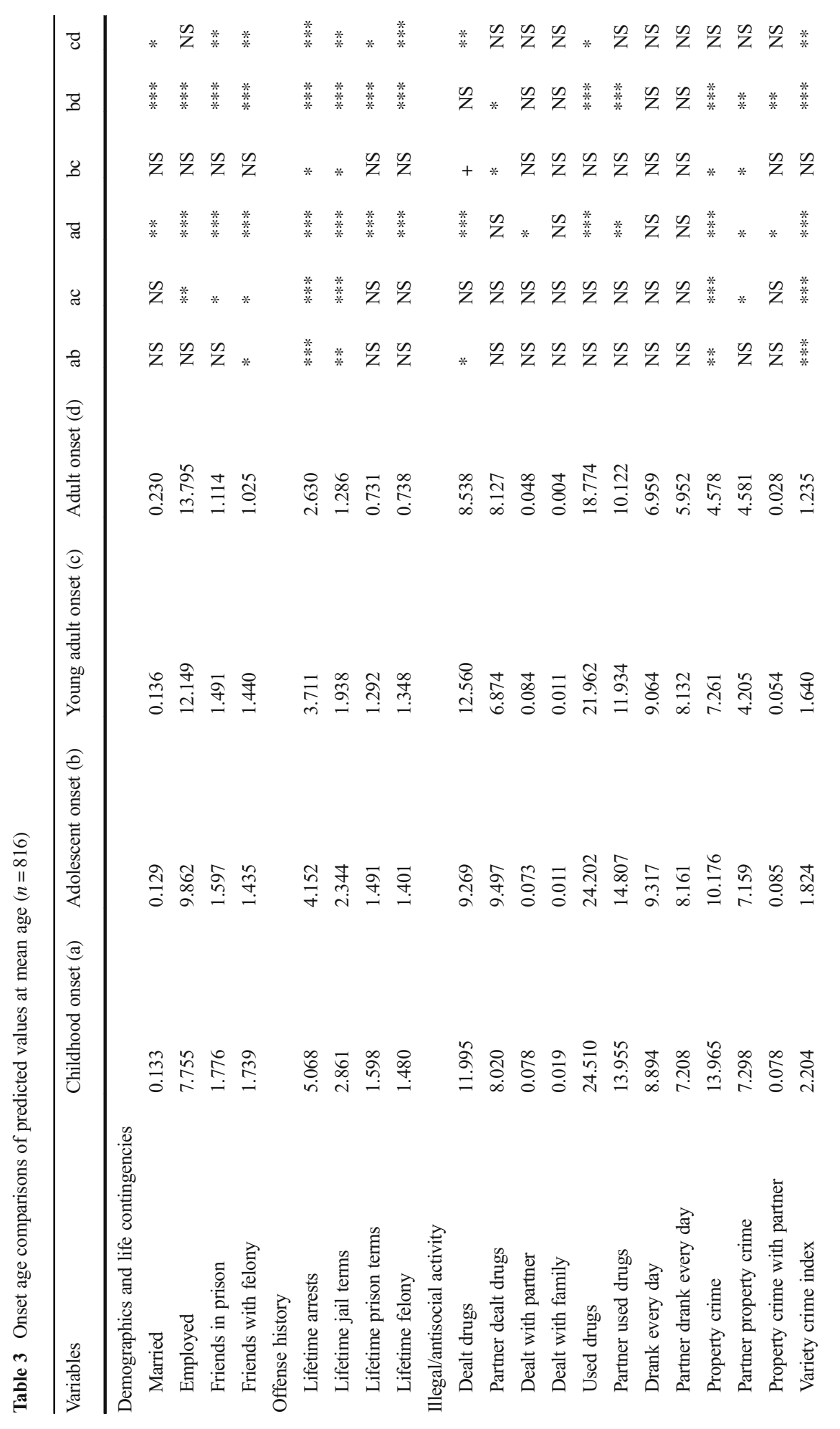




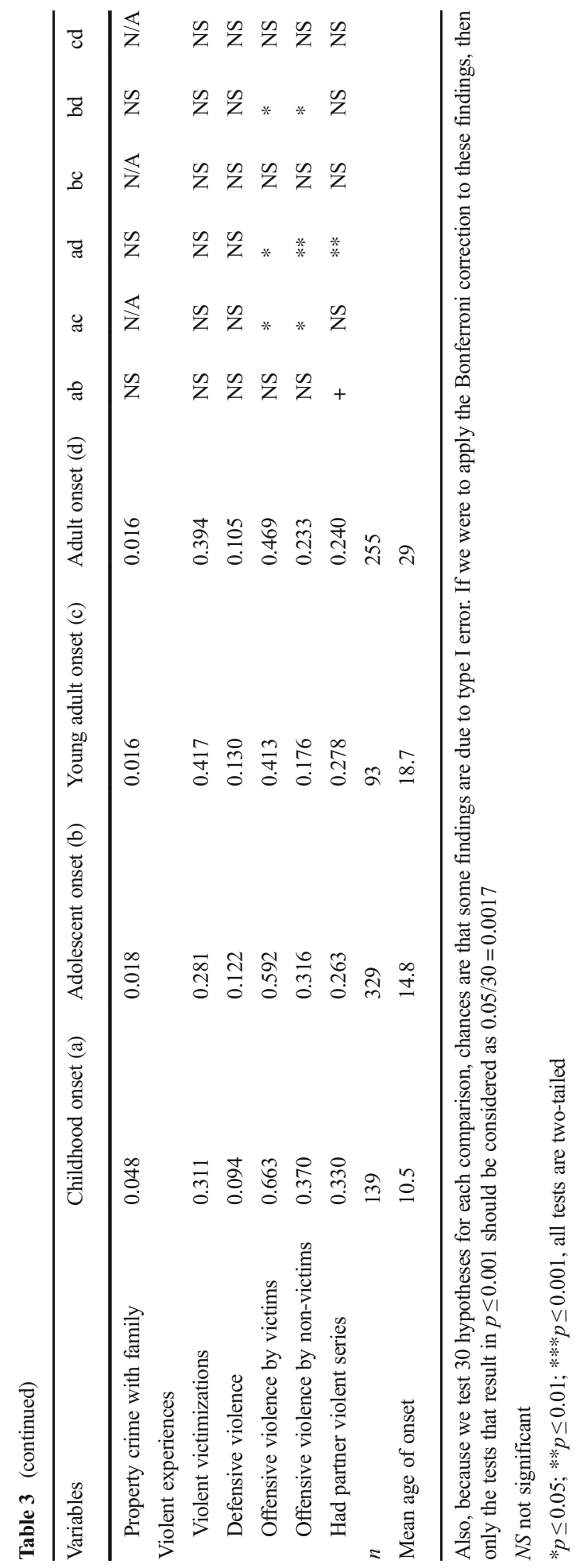




\section{Summary}

Our analysis of age-graded pathways to jail produced several noteworthy findings. Our first observation is that place matters. The multinomial regressions showed increased odds of childhood- and adolescent-onset groups (compared with adults) for the Minnesota site. This suggests that findings from one-site studies are potentially nongeneralizable, accounting for some of the large discrepancies in the proportion of adult initiators across studies. Further, we found that predictors of adult onset are affected by how adult onset is measured. Young adult initiators (ages 18-20) appear to be more similar to adult than child starters as they display substantially different risk factors compared to childhood starters (childhood sex abuse and lack of childhood bonds) and adolescent starters (childhood bonds, sexual precocity, first sex in adolescence). In this respect, they are similar to the late bloomers identified in other research. The observed differences between adolescent and young adults are notable because the average age of onset within the adolescent and young adult groups is not all that different (14.8 versus 18.7, respectively) compared with the average age of 29 for the adult initiators.

We did find, however, a number of important differences between the young adult starters and adults when we examined post-initiation variables. On average, the young adults tend to have a more extensive offending history (e.g., arrests, jail and prison terms, and felony convictions) and associate with criminal friends more than do the adults. They have somewhat higher drug involvement (use/dealing) and more offense variety. And they are less likely to have been married at the time of the interview. For these reasons, we believe that the 18-20-year olds in our sample may be more similar to the late bloomers identified by Thornberry and Krohn [53] who delay onset vis-à-vis other adolescent initiators because they are buffered by strong social bonds (supportive family). However, once they strike out on their own (around age 18), their "human capital" deficits create the conditions under which offending increases. Lower intelligence, emotional issues, and lack of academic success increase the likelihood that life stressors "due to problems encountered in both employment and relationship trajectories" increase the risk that late bloomers will begin serious offending later in life than the "model years during adolescence" ([33], p. 191). Unique to our findings, however, is that unlike the Rochester Youth Development Study sample collected and analyzed by Thornberry and his associates (including Sohoni et al. 2014), we have identified a sizeable adult-onset population that, while similar in some respects, is quite distinct from the young adult initiators in others. This group reveals no obvious deficits and no clear risk factors. In our data, at least, the adult-onset offender appears to be fundamentally distinct.

Sohoni and her associates (2014) identify the weakness of previous studies that rely on official records and the utilization of legal definitions to classify first time offenders and adult status. We concur that previous studies are problematic for the reasons they have identified but reject their conclusion that "there is no distinctive category of offenders who onset in adulthood" (p. 168). Our adult initiators, rather than demonstrating continuity of antisocial behavior from childhood, show few of the same risk factors associated with offending in the other groups. Our results may be due to the nature of our sample (i.e., all of the women were incarcerated) or it may point to some important causal mechanism related to gender that increases the likelihood or risk of adult initiation. Our adult starters are not characterized by childhood sexual abuse, and initiation is not tied to early physical abuse. Post-offending, they appear not to be 
deeply immersed in the drug culture. There is no clear predictor of adult onset - we only know what does not predict initiation compared with childhood, adolescent, and young adult initiators, and on the whole, they have better post-offending outcomes.

Although we have focused most of our attention on the adult-onset group, our research has also uncovered important characteristics that distinguish childhood and adolescent onset. Early sexual abuse, first sex in childhood, lack of childhood bonds, and poor parental supervision substantially increase the risk of childhood initiation (relative to initiation into crime at an older age) - results that are consistent with the extant literature [50]. We also show that precocious (before age 12) and adolescence sexual initiation as well as a lack of childhood bonds increase the risk of adolescent onset (compared with adult initiation). The mechanisms of these risks (e.g., maturity gap between physical development and social constraints and/or more attention by older males) cannot be unraveled in these data, but the findings are consistent when childhood initiators are dropped from the comparisons (Table 2).

Finally, consistent with the notion of behavioral stability, childhood onsetters are significantly associated with post-onset property crime, more offense variety, and more lifetime arrest and jail terms than other groups. They also are more likely than other onset groups to use violence than early or later adult initiators and to experience more series violence (both with and without partners) than most of the other groups. Again, these findings are not unexpected. In Giordano's Ohio Life-Course Study [25], she reports that early exposure and socialization toward violence may be associated with a greater risk of other kinds of violence in adulthood, especially for women who report higher levels of delinquent involvement during their teen years. While our data do not allow us to disentangle whether these outcomes stem from persistent heterogeneity or state dependence, there is no question that childhood initiation has set these women on an offending/ sanction trajectory that is, in many ways, distinct from the other onset groups.

\section{Limitations and Next Steps}

Although the jury is still out on the issue of adult onset, this analysis has revealed both a distinct group of young adult female offenders and a sizeable population of adult-onset offenders. These are intriguing findings, given that other scholars simply cannot find substantial numbers of adult initiators [42] or that late bloomers do not look any different from other offenders in terms of their offending trajectories (Sohoni et al. 2014). Because our data are limited by the retrospective nature of our data collection techniques (e.g., 3 years of data prior to respondents' current incarceration with some static life history information) and the population (female, all incarcerated offenders), we are unable to examine some of the key criminal career dimensions from age of onset with this population (e.g., frequency, type of offending, desistance), utilize some of the more popular data analysis techniques comparing offending patterns (trajectories), or even map out individual continuity and discontinuity from childhood through adulthood. We also do not have access to information that would capture neurological or psychological differences predicted to distinguish juveniles from adults. And due to the large number of comparisons in our analyses, it is likely that some of the reported differences are not, in fact, statistically significant. However, we have observed interesting patterns and distinctions between onset groups and can, in the future, examine whether other factors such as stress and social instability (mobility, number of partners, job change) provide a better idea about the mechanisms of adult onset in a population of female offenders. 


\section{Appendix}

Table 4 Variable descriptions

\begin{tabular}{lll}
\hline Variable & $\begin{array}{l}\text { Possible } \\
\text { values }\end{array}$ & Description \\
\hline
\end{tabular}

\begin{tabular}{|c|c|c|c|}
\hline \multicolumn{4}{|c|}{ Demographics and life contingencies } \\
\hline $\begin{array}{l}\text { Age at current } \\
\text { arrest }\end{array}$ & {$[18, \infty]$} & Respondent's age at time of current arrest & $34.196(8.458)$ \\
\hline $\begin{array}{l}\text { African } \\
\text { American }\end{array}$ & 0,1 & Respondent's race/ethnicity is African American & $0.494(0.500)$ \\
\hline Native American & 0,1 & Respondent's race/ethnicity is Native American & $0.097(0.296)$ \\
\hline White & 0,1 & Respondent's race/ethnicity is White & $0.368(0.483)$ \\
\hline Other & 0,1 & Respondent is other race/ethnicity & $0.042(0.200)$ \\
\hline $\begin{array}{l}\text { High school } \\
\text { graduate/GED }\end{array}$ & 0,1 & Respondent graduated high school or obtained her GED & $0.491(0.500)$ \\
\hline Married & 0,1 & Respondent was married at the time of current arrest & $0.167(0.373)$ \\
\hline Employed & {$[0,36]$} & Number of months the respondent had a job & $10.984(12.712)$ \\
\hline $\begin{array}{l}\text { Raised by both } \\
\text { parents }\end{array}$ & 0,1 & Respondent was raised by both biological parents & $0.397(0.490)$ \\
\hline $\begin{array}{l}\text { Childhood } \\
\text { physical abuse }\end{array}$ & {$[0,4]$} & $\begin{array}{l}\text { Scale measuring respondent's experiences of childhood } \\
\text { physical abuse by primary caretaker (e.g., twisted arm } \\
\text { or hair, slammed against wall, punched or hit, choked, } \\
\text { beat up, burned or scalded on purpose, kicked, used } \\
\text { knife or gun, caused sprain/bruise/cut, caused to pass } \\
\text { out, caused to go to doctor). Possible responses were } \\
\text { never, once or twice, sometimes, frequently, or most of } \\
\text { the time }\end{array}$ & $0.239(.487)$ \\
\hline
\end{tabular}

$\begin{array}{ccc}\begin{array}{c}\text { Childhood } \\ \text { sexual abuse }\end{array} & 0,1 \quad \begin{array}{c}\text { Respondent was sexually abused before 6th grade (e.g., } \\ \text { showed or was shown sex organs, fondled/touched sex } \\ \text { organs or fondled/touched, attempted intercourse). Only } \\ \text { includes incidents the respondent defined as sexual } \\ \text { abuse at the time the acts occurred }\end{array} \\ \begin{array}{c}\text { First sex in } \\ \text { childhood }\end{array} & 0,1 \quad \begin{array}{c}\text { Dummy variable indicating that the respondent reported } \\ \text { first having sex at age } 12 \text { or under }\end{array} \\ \begin{array}{c}\text { First sex in } \\ \text { adolescence }\end{array} & 0,1 \quad \begin{array}{c}\text { Dummy variable indicating that the respondent reported } \\ \text { first having sex between ages } 13 \text { and } 17\end{array}\end{array}$

Family variables
Lack of supervision

$[2,8]$ Scale measuring lack of supervision during childhood

How often primary caregiver knew whereabouts when away from home

How often primary caregiver knew whom with when away from home, coded such that higher values indicate less often/lack of supervision $(1=$ almost always; 4 = almost never)

Lack of childhood bonds
[9, 31] Scale measuring lack of bonds during childhood How often respondent knew where at least one parent was How often respondent discussed problems with primary caregiver 
Table 4 (continued)

\begin{tabular}{lll} 
Variable & $\begin{array}{l}\text { Possible Description } \\
\text { values }\end{array}$ & Mean (SD) \\
\hline
\end{tabular}

How often primary caregiver asked what respondent doing in school

How often respondent shared thoughts/feelings with primary caregiver

How often respondent felt unwanted by primary caregiver

How often primary caregiver praised respondent

Number of friends primary caregiver knew

How happy family was when growing up, higher values indicating a lack of bonds, possible values range from 8 to 33

\begin{tabular}{|c|c|c|}
\hline $\begin{array}{l}\text { Parents' } \\
\text { disapproval of } \\
\text { violence }\end{array}$ & {$[2,6]$} & $\begin{array}{l}\text { Scale measuring disapproval of violence. If another } \\
\text { kid insulted you and you physically attacked him/he } \\
\text { how would your mother (or female caretaker) or fat } \\
\text { (or male caretaker) have reacted? Higher values indic } \\
\text { greater disapproval }\end{array}$ \\
\hline $\begin{array}{l}\text { Religion } \\
\text { education }\end{array}$ & 0,1 & $\begin{array}{l}\text { How much religious education or training did you } \\
\text { receive as a child? A lot/some vs. a little or none }\end{array}$ \\
\hline Welfare & 0,1 & $\begin{array}{l}\text { When you were growing up, did your family ever rec } \\
\text { welfare or public assistance, like food stamps, aid } \\
\text { dependent children, or Medicaid? Most of the } \\
\text { time/frequently vs. never/occasionally }\end{array}$ \\
\hline Lifetime arrests & {$[1,7]$} & $\begin{array}{l}\text { Scale measuring the number of times the respondent } \\
\text { arrested (possible responses were } 1 \text { time, } 2-3 \text { times, } \\
4-6,7-10,11-15,16-25 \text {, or more than } 25 \text { times) }\end{array}$ \\
\hline $\begin{array}{l}\text { Lifetime jail } \\
\text { terms }\end{array}$ & {$[0,7]$} & $\begin{array}{l}\text { Scale measuring the number of terms the respondent } \\
\text { served in jail (possible responses were no times, } 1 \text { tir } \\
2-3 \text { times, } 4-6,7-10,11-15,16-25 \text {, or more than } 2 \\
\text { times) }\end{array}$ \\
\hline $\begin{array}{l}\text { Lifetime prison } \\
\text { terms }\end{array}$ & {$[0,7]$} & $\begin{array}{l}\text { Scale measuring the number of terms the respondent } \\
\text { served in prison (possible responses were no times, } \\
1 \text { time, } 2-3 \text { times, } 4-6,7-10,11-15,16-25 \text {, or mor } \\
\text { than } 25 \text { times) }\end{array}$ \\
\hline Lifetime felony & {$[0,6]$} & $\begin{array}{l}\text { Scale measuring the number of times the respondent } \\
\text { convictions was convicted of a felony (possible } \\
\text { responses were no times, } 1 \text { time, } 2-3 \text { times, } 4-6 \text {, } \\
7-10,11-15,16-25 \text {, or more than } 25 \text { times) }\end{array}$ \\
\hline
\end{tabular}

$0.401(0.490)$

Illegal/antisocial activity

\begin{tabular}{|c|c|c|}
\hline Dealt drugs & {$[0,36]$} & Number of months the respondent dealt drugs \\
\hline $\begin{array}{l}\text { Partner dealt } \\
\text { drugs }^{\mathrm{a}}\end{array}$ & {$[0,36]$} & $\begin{array}{l}\text { Number of months the respondent had a partner } \\
\text { who dealt drugs }\end{array}$ \\
\hline $\begin{array}{l}\text { Dealt with } \\
\text { partner }\end{array}$ & 0,1 & Respondent dealt drugs with a partner \\
\hline Dealt with family & 0,1 & Respondent dealt drugs with a family member \\
\hline Used drugs & {$[0,36]$} & $\begin{array}{l}\text { Number of months the respondent used drugs } \\
\text { (e.g., marijuana, crack, cocaine, heroin, } \\
\text { speed, acid, other drugs) }\end{array}$ \\
\hline $\begin{array}{l}\text { Partner used } \\
\text { drugs }\end{array}$ & {$[0,36]$} & $\begin{array}{l}\text { Number of months the respondent had a partner } \\
\text { who used drugs }\end{array}$ \\
\hline
\end{tabular}
(e.g., marijuana, crack, cocaine, heroin, 
Table 4 (continued)

\begin{tabular}{|c|c|c|c|}
\hline Variable & $\begin{array}{l}\text { Possible } \\
\text { values }\end{array}$ & Description & Mean (SD) \\
\hline Drank every day & {$[0,36]$} & $\begin{array}{l}\text { Number of months the respondent drank alcohol } \\
\text { every day }\end{array}$ & $8.474(13.220)$ \\
\hline $\begin{array}{l}\text { Partner drank } \\
\text { every day }\end{array}$ & {$[0,36]$} & $\begin{array}{l}\text { Number of months the respondent had a partner who } \\
\text { drank alcohol every day }\end{array}$ & $7.322(12.148)$ \\
\hline Property crime & {$[0,36]$} & $\begin{array}{l}\text { Number of months the respondent committed property } \\
\text { crime (e.g., theft, prostitution, burglary, auto theft, } \\
\text { fraud, forgery) }\end{array}$ & $8.747(12.228)$ \\
\hline $\begin{array}{l}\text { Partner property } \\
\text { crime }^{\mathrm{a}}\end{array}$ & {$[0,36]$} & $\begin{array}{l}\text { Number of months the respondent had a partner who } \\
\text { committed property crime }\end{array}$ & $6.018(11.773)$ \\
\hline $\begin{array}{l}\text { Property crime } \\
\text { with partner }\end{array}$ & 0,1 & Respondent committed property crime with partner & $0.062(0.242)$ \\
\hline $\begin{array}{l}\text { Property crime } \\
\text { with family }\end{array}$ & 0,1 & $\begin{array}{l}\text { Respondent committed property crime with other } \\
\text { family member }\end{array}$ & $0.021(0.143)$ \\
\hline \multicolumn{4}{|l|}{ Violent experiences } \\
\hline $\begin{array}{l}\text { Violent } \\
\text { victimizations }\end{array}$ & {$[0,16]$} & $\begin{array}{l}\text { Number of unique incidents in which a non-violent } \\
\text { respondent experienced a partner or non-partner } \\
\text { violent victimization (e.g., assault, rape, robbery) }\end{array}$ & $0.335(0.960)$ \\
\hline $\begin{array}{l}\text { Defensive } \\
\text { violence }\end{array}$ & {$[0,16]$} & $\begin{array}{l}\text { Number of unique incidents in which a non-offensively } \\
\text { violent respondent used defensive violence against } \\
\text { a partner }\end{array}$ & $0.112(0.439)$ \\
\hline $\begin{array}{l}\text { Offensive } \\
\text { violence by } \\
\text { victims }\end{array}$ & {$[0,16]$} & $\begin{array}{l}\text { Number of unique incidents in which a victimized } \\
\text { respondent used offensive violence against a partner } \\
\text { or non-partner }\end{array}$ & $0.543(1.164)$ \\
\hline $\begin{array}{l}\text { Offensive } \\
\text { violence by } \\
\text { non-victims }\end{array}$ & {$[0,16]$} & $\begin{array}{l}\text { Number of unique incidents in which a non-victimized } \\
\text { respondent used offensive violence against a partner } \\
\text { or non-partner }\end{array}$ & $0.282(0.797)$ \\
\hline $\begin{array}{l}\text { Had partner } \\
\text { violent series }\end{array}$ & 0,1 & $\begin{array}{l}\text { Respondent reported at least one partner violent series } \\
\text { of incidents }\end{array}$ & $0.274(0.446)$ \\
\hline $\begin{array}{l}\text { Had non-partner } \\
\text { violent series }\end{array}$ & 0,1 & $\begin{array}{l}\text { Respondent reported at least one non-partner violent } \\
\text { series of incidents }\end{array}$ & $0.086(0.280)$ \\
\hline
\end{tabular}

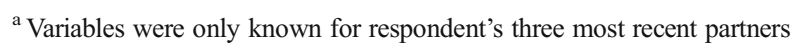

\section{References}

1. Baskin, D. R., \& Sommers, I. B. (1993). 'Females' initiation into violent street crime. Justice Quarterly, 10(December), 559-584.

2. Baskin, D. R., \& Sommers, I. B. (1997). Casualties of community disorder. Boulder: Westview.

3. Becker, S., \& Diop-Sidibe, N. (2003). Does use of the calendar in surveys reduce heaping? Studies in Family Planning, 34(2), 127-132.

4. Becker, S., \& Sosa, D. (1992). An experiment using a month-by-month calendar in a family planning survey in Costa Rica. Studies in Family Planning, 23(6), 386-391.

5. Belli, R. F. (1998). The structure of autobiographical memory and the event history calendar: potential improvements in the quality of retrospective reports in surveys. Memory, 6(4), 383-406.

6. Belli, R. F., Shay, W. L., \& Stafford, F. P. (2001). Event history calendars and question list surveys: a direct comparison of interviewing methods. Public Opinion Quarterly, 65, 45-74. 
7. Bernburg, J. G., \& Krohn, M. D. (2003). Labeling, life chances, and adult crime: the direct and indirect effects of official intervention in adolescence on crime in early adulthood. Criminology, 41, 1287-1318.

8. Block, C. R., Blockland, A. A. J., van der Werff, C., van Os, R., \& Nieuwbeerta, P. (2010). Long-term patterns of offending in women. Feminist Criminology, 5(1), 73-107.

9. Blumstein, A., Cohen, J., Roth, J. A., \& Visher, C. A. (1986). Criminal careers and 'career criminals'. Washington, DC: National Academy Press.

10. Bor, W., McGee, T. R., Hayatbakhsh, R., Dean, A., \& Najman, J. M. (2010). Do antisocial females exhibit poor outcomes in adulthood? An Australian cohort study. Australian and New Zealand Journal of Psychiatry, 44(7), 648-657.

11. Cairns, R. B., \& Kroll, A. B. (1994). A developmental perspective on gender differences and similarities. In M. L. Rutter, D. F. Hay, \& S. Baron-Cohen (Eds.), Developmental principles and clinical issues in psychology and psychiatry (pp. 330-372). Oxford: Blackwell Scientific.

12. Carbone-Lopez, K., \& Miller, J. (2012). Precocious role entry as a mediating factor in women's methamphetamine use: implications for life-course and pathways research. Criminology, 50, 187-220.

13. Carr, N. T., \& Hanks, R. S. (2012). If "60 is the new 40", is 35 the new 15? Late onset crime and delinquency. Deviant Behavior, 33(5), 393-411.

14. Carrington, B., Tymms, P. \& Merrell, C. (2005). Role models, school improvement and the 'gender gap'-do men bring out the best in boys and women the best in girls? Paper presented to the European Association for Research on Learning and Instruction, University of Nicosia. Available: http:/www. cemcentre.org/news/

15. Caspi, A., Moffitt, T. E., Thornton, A., Freedman, D., Amel, J. W., Harrington, H., Smeijers, J., \& Silva, P. A. (1996). The life history calendar: a research and clinical assessment method for collecting retrospective event-history data. International Journal of Methods in Psychiatric Research, 6, 101-114.

16. Cauffman, E., \& Steinberg, L. (2000). (Im)maturity of judgment in adolescence: why adolescents may be less culpable than adults. Behavioral Science and Law, 18, 742-743.

17. Couture, H. (2009). Criminal onset in emerging adulthood. College Park: University of Maryland. Dissertation.

18. Dannefer, D. (2003). Cumulative advantage/disadvantage and the life 'course': cross-fertilizing age and social science theory. Journal of Gerontology (Series B), 58, S327-S337.

19. DeLisi, M. (2002). Not just a boys club: an empirical assessment of female career criminals. Women and Criminal Justice, 13, 27-46.

20. Eggleston, E. P., \& Laub, J. H. (2002). The onset of adult offending: a neglected dimension of the criminal career. Journal of Criminal Justice, 30, 603-622.

21. Elder, G. H. (1998). The life course as developmental theory. Child Development, 69, 1-12.

22. Engel, L. S., Keifer, M. C., \& Zahml, S. H. (2001). Comparison of a traditional questionnaire with an icon/calendar-based questionnaire to assess occupational history. American Journal of Industrial Medicine (Special Issue: Feasibility of Epidemiologic Research on Migrant and Seasonal Farmworkers), 40(5), 502-511.

23. Farrington, D. P., Lambert, S., \& West, D. J. (1998). Criminal careers of two generations of family members in the Cambridge study of delinquent development. Crime and Crime Prevention, 7, 85-97.

24. Farrington, D.P. \& Painter, K. (2004). Gender differences in risk factors for offending. Great Britain home office. Communication Development Unit Room 264, Home Office 50 Queen Anne's Gate Research Development and Statistics Directorate London SW1H 9AT, United Kingdom. http:/www.homeoffice. gov.uk/rds/onlinepubs1.html

25. Giordano, P. C. (2010). Legacies of crime: a follow-up of the children of highly delinquent girls and boys. New York: Cambridge University Press.

26. Glasner, T., \& Van der Vaart, W. (2009). Applications of calendar instruments in social surveys: a review. Quality and Quantity, 43, 333-349.

27. Goldman, N., Moreno, L., \& Westoff, C. F. (1989). Collection of survey data on contraception: an evaluation of an experiment in Peru. Studies in Family Planning, 20, 147-157.

28. Gomez-Smith, Z. (2004). An examination of adult onset offending. MA thesis, University of Florida

29. Gomez-Smith, Z., \& Piquero, A. R. (2005). An examination of adult onset offending. Journal of Criminal Justice, 33(6), 515-525.

30. Gunnison, E., \& McCartan, L. M. (2010). Persistent versus late onset among female offenders: a test of state dependent and population heterogeneity interpretations. Western Criminology Review, 11(3), 45-62.

31. Hayatbakhsh, M. R., Najman, J. M., McGee, T. R., Bor, W., \& O'Callaghan, M. J. (2008/2009). Early pubertal maturation in the prediction of early adult substance use: a prospective study. Addiction, 104, 5966. (Version of Record online: 3 Nov 2008. doi:10.1111/j.13600443.2008.02382.x). 
32. Horney, J. (2001). Criminal events and criminal careers. In Meier, Robert Leslie Kennedy and Vincent Sacco (eds), The process and structure of crime: criminal events and crime analysis (pp. 141-168). New Brunswick, N.J.: Transaction

33. Krohn, M. D., Gibson, C. L., \& Thornberry, T. P. (2013). Under the protective bud the bloom awaits: a review of theory and research on adult-onset and late-blooming offenders. In M. D. Krohn, C. L. Gibson, \& T. P. Thornberry (Eds.), Handbook of life-course criminology: emerging trends and directions for future research (pp. 183-199). New York: Springer.

34. Kratzer, L., \& Hodgins, S. (1999). A typology of offenders: a test of Moffitt's theory among males and females from childhood to age 30. Criminal Behaviour and Mental Health, 9(1), 57-73.

35. Laub, J. H., \& Sampson, R. J. (1997). A life-course theory of cumulative disadvantage and the stability of delinquency. In T. P. Thornberry (Ed.), Developmental theories of crime and delinquency (pp. 133-161). New Brunswick: Transaction.

36. Laub, J. H., \& Sampson, R. J. (2003). Shared beginnings, divergent lives: delinquent boys to age 70. Cambridge: Harvard University Press.

37. Le Blanc, M., \& Loeber, R. (1998). Developmental criminology updated. In M. Tonry (Ed.), Crime and justice: a review of research (Vol. 23, pp. 115-198). Chicago: Chicago University Press.

38. Lopes, G., Krohn, M. D., Lizotte, A. J., Schmidt, N. M., Vàsquez, B. E., \& Bernburg, J. G. (2012). Labeling and cumulative disadvantage: the impact of formal police intervention on life chances and crime during emerging adulthood. Crime and Delinquency, 38, 456-488.

39. McGee, T. R., \& Farrington, D. P. (2010). Are there any true adult-onset offenders? The British Journal of Criminology, 50(3), 530-549.

40. Moffitt, T. E. (1993). Adolescence-limited and life-course-persistent antisocial behavior: a developmental taxonomy. Psychological Review, 100(4), 674-701.

41. Moffitt, T. E. (1994). Natural histories of delinquency. In H. J. Kerner \& E. Weitekamp (Eds.), Crossnational longitudinal research on human development and criminal behaviour (pp. 3-64). Dordrecht: Kluwer Academic.

42. Moffitt, T. E., Caspi, A., Rutter, M., \& Silva, P. A. (2001). Sex differences in antisocial behaviour: conduct disorder, delinquency, and violence in the Dunedin Longitudinal Study. Cambridge: Cambridge University Press.

43. Morris, N. A., \& Slocum, L. A. (2010). The validity of self-reported prevalence, frequency and timing of arrest: an evaluation of data collected using a life events calendar. Journal of Research in Crime and Delinquency, 47, 210-240.

44. Patterson, G. R., Capaldi, D., \& Bank, L. (1991). An early starter model for predicting delinquency. In D. Pepler \& K. H. Rubin (Eds.), The development and treatment of childhood aggression (pp. 139-168). Hillsdale: Lawrence Erlbaum Associates.

45. Piquero, A. R., Farrington, D. P., \& Blumstein, A. (2007). Key issues in criminal career research: new analyses of the Cambridge study in delinquent development. New York: Cambridge University Press.

46. Roberts, J., \& Horney, J. (2010). The life event calendar method in criminological research. In A. Piquero \& D. Weisburd (Eds.), Handbook of quantitative criminology (pp. 289-312). New York: Springer.

47. Rutter, M., \& Rutter, M. (1993). Developing minds: challenge and continuity across the life span. New York: Basic Books.

48. Sampson, R. J., \& Laub, J. H. (1993). Crime in the making: pathways and turning points through life. Cambridge: Harvard University Press.

49. Simpson, S. S., Yahner, J. L., \& Dugan, L. (2008). Understanding women's pathways to jail: a life history analysis of the lives of incarcerated women. Australian and New Zealand Journal of Criminology, 41, 84-108.

50. Shader, M. (2004). Risk factors for delinquency: an overview. Washington, DC: US Department of Justice, Office of Justice Programs, OJJDP.

51. Sohoni, T., Paternoster, R., McGloin, J. M., \& Bachman, R. (2011). Hen's teeth and horse's toes: the adult onset offender in criminology. Paper presented at the Stokholm Criminology Symposium, Stockholm, Sweden.

52. Sohoni, T., Paternoster, R., McGloin J. M., \& Bachman, R. (2014). Hen's teeth and horse's toes: the adult onset offender in criminology. Journal of Crime and Justice, 37(2), 155-172.

53. Thornberry, T. P., \& Krohn, M. D. (2005). Applying interactional theory to the explanation of continuity and change in antisocial behavior. In D. P. Farrington (Ed.), Integrated developmental and life-course theories of offending (pp. 183-209). New Brunswick: Transaction.

54. Thornberry, T.P. \& Matsuda, M. (2011). Why do late bloomers wait? An examination of factors that delay the onset of offending. Presented at the Stockholm Criminology Symposium, Stockholm, Sweden

55. Tolan, P. H., \& Thomas, P. (1995). The implications of age of onset for delinquency risk II: longitudinal evidence. Journal of Abnormal Child Psychology, 23, 157-181. 
56. Tracy, P., \& Kempf-Leonard, K. (1996). Continuity and discontinuity in criminal careers. NY: Plenum.

57. Stattin, H., Magnusson, D., \& Reichel, H. (1989). Criminal activity at different ages: a study based on a Swedish longitudinal research population. British Journal of Criminology, 29, 368-385.

58. Vander Vaart, W. (1996). Inquiring into the past. Data quality of responses to retrospective questions. PhD-thesis. Amsterdam: Vrije Universiteit.

59. Van der Vaart, W. (2004). The time-line as a device to enhance recall in standardized research interviews: a split ballot study. Journal of Official Statistics, 20, 301-317.

60. Van der Vaart, W. \& Glasner, T.J. (2005). Enhancing recall accuracy in surveys by cognitively tailored timeline methods: a record check study. Paper presented at the First EASR Conference, Barcelona (2005)

61. White, N., \& Piquero, A. (2004). A preliminary empirical test of Silverthorn and Frick's delayed-onset pathway in girls using an urban, African-American, US-based sample. Criminal Behaviour and Mental Health, 14, 291-309.

62. Wikström, P. O. H. (1990). Age and crime in a Stockholm cohort. Journal of Quantitative Criminology, 6(1), 61-84.

63. Yoshihama, M., Gillespie, B., Hammock, A., Belli, R. F., \& Tolman, R. (2005). Does the life-history calendar method facilitate the recall of domestic violence victimization? Comparison of two methods of data collection. Social Work Research, 29(3), 151-163.

64. Zara, G., \& Farrington, D. P. (2009). Childhood and adolescent predictors of late onset criminal careers. Journal of Youth and Adolescence, 38, 287-300. 